\title{
Inter-relationships between inflammatory markers in patients with stable COPD with bronchitis: intra- patient and inter-patient variability
}

\author{
E Sapey, ${ }^{1}$ D Bayley, ${ }^{1}$ A Ahmad, ${ }^{2}$ P Newbold, ${ }^{3}$ N Snell, ${ }^{3}$ R A Stockley ${ }^{1}$
}

- Tables E1-E5 and figures 2-5 are published online only at http://thorax.bmj.com/content/ vol63/issue6

${ }^{1}$ Department of Respiratory Medicine, University Hospital Birmingham, Birmingham, UK;

${ }^{2}$ Department of Medicine,

University of Birmingham,

Birmingham, UK; ${ }^{3}$ Astra Zeneca

R\&D Charnwood, Loughborough,

Leicestershire, UK

Correspondence to:

Professor R A Stockley,

Department of Respiratory

Medicine, First Floor, Nuffield

House, University Hospital

Birmingham, Edgbaston,

Birmingham B15 2TH, UK;

r.a.stockley@bham.ac.uk

Received 11 July 2007

Accepted 2 November 2007

Published Online First

23 November 2007

\section{ABSTRACT}

Background: Measurements of pulmonary biomarkers can be used to monitor airway inflammation in chronic obstructive pulmonary disease (COPD), but the variability of sampled biomarkers and their inter-relationships are poorly understood. A study was undertaken to examine the intra- and inter-patient variability in spontaneous sputum samples from patients in the stable state and to describe the relationship between biomarkers, cell counts and markers of disease.

Methods: Sputum interleukin-1 $\beta$, tumour necrosis factor $\alpha$, interleukin 8, myeloperoxidase, leucotriene B4, growthrelated oncogene $\alpha$ and differential cell counts were measured in patients with moderate to severe stable COPD ( $n=14$ ) on 11 occasions over a 1-month period.

Results: There was significant variability in all inflammatory indices (median intra-patient coefficient of variation (CV) 35\% (IOR 22-69), median inter-patient CV 102\% (IOR 61-145)). Variability could be reduced by using a rolling mean of individual patient data points. Sample size calculations were undertaken to determine the number of patients required to detect a $50 \%$ reduction in neutrophil count. Using a crossover design of a putative effective treatment, the number needed using one data point per patient was 72, reducing to 23 when a mean of three data points was used. Significant correlations were demonstrated both between the inflammatory biomarkers themselves and between inflammatory biomarkers and markers of disease. Some relationships were not apparent when results from a single sample were used. The reliability of inter-relationships improved as more data points were used for each patient.

Conclusions: Clear relationships exist between inflammatory biomarkers in patients with stable COPD.

Sequential sampling reduced the variability of individual mediators and the potential number of patients needed to power proof of concept interventional studies.

It is widely accepted that chronic obstructive pulmonary disease (COPD) is an inflammatory condition. and many inflammatory mediators and their corresponding receptors have been highlighted as potential targets for specific antiinflammatory therapeutic intervention. ${ }^{1}$ Some of these agents have been used in limited studies, such as antibodies directed against tumour necrosis factor $\alpha(\mathrm{TNF} \alpha)^{2}$ and interleukin $8(\mathrm{CXCL} 8)^{3}$ and small molecule antagonists of leucotriene B4 (LTB4), ${ }^{4}$ while other anti-inflammatory agents are under development with the anticipation of clinical trials in the future. ${ }^{1}$

In drug development for COPD there is a need to conduct small short-term phase 2 trials to identify biological and efficacy read-outs for novel therapeutic agents. Conventional physiological tests are often inappropriate for the early investigation of drugs with potential disease-modifying antiinflammatory activity since these trials would be relatively long, involving large patient numbers and hence prohibitively expensive. For this reason, disease-related biomarkers are considered to be the appropriate candidates for initially investigating drug efficacy in disease. Recent studies have listed biomarkers which correlate with disease severity and BODE index, ${ }^{5}$ but there is little information about the reproducibility of measurements and the relationship of these indices to other inflammatory mediators, disease development, severity and progression. ${ }^{6}$ Only sputum neutrophils, CXCL8, TNF $\alpha$ and $\mathrm{C}$-reactive protein have successfully differentiated between the differing stages of COPD, ${ }^{6}$ although other studies have shown associations between different biomarkers both when stable and during exacerbations.

The majority of interventional studies have relied upon a single pre- and post-interventional measurement of a biomarker to ascertain any change. ${ }^{18}$ However, without knowledge of the inherent variability of the factor being used, it is difficult to perform the calculations required to ensure that a study has sufficient power to detect a relevant difference, and this will be critical in determining the role of an individual mediator in the inflammatory cascade and the decision to proceed to larger studies to determine clinical benefit.

The purpose of the present study, therefore, was twofold: (1) to describe the variability in inflammatory indices in spontaneous sputum in stable COPD and to assess the effect of multiple sampling to reduce this variability; and (2) to assess the relationship between some mediators that have been implicated in the pathogenesis of COPD.

\section{METHODS}

\section{Study subjects}

Patients aged 50-78 years with a diagnosis of GOLD stage III COPD ${ }^{9}$ were recruited. They were daily sputum producers with a history of chronic bronchitis as defined by the MRC criteria ${ }^{10}$ and were current or ex-smokers. All patients were confirmed to have obstructive airways disease at screening by spirometric measurements and had stable symptoms of COPD for at least 8 weeks prior to recruitment with no changes in medication during this time. Alternative and concomitant lung 
disease was excluded clinically and by high-resolution CT scanning.

\section{Study design}

Patients were seen on 11 occasions over 4 weeks (daily for 5 days, then twice weekly for 3 weeks). On each visit the patients were reviewed, symptoms were noted and samples of spontaneous sputum and blood were collected. Spirometry was assessed weekly to assess disease stability.

Patients were asked to complete daily diary cards, described previously, ${ }^{11}$ throughout the study. Symptoms (including dyspnoea, sputum volume and colour) were recorded using an ordinal scale which allowed differentiation between normal for the patient and better or worse than usual to ensure that there were no changes suggestive of an exacerbation.

\section{Sample collection and processing}

Spontaneous sputum samples were collected over $4 \mathrm{~h}$ (from rising in the morning) following mouth-washing procedures to minimise salivary contamination. Sputum collection and analysis occurred at the same time on each visit. The samples were divided into two aliquots: the first was ultracentrifuged (50 $000 \mathrm{~g}$ for $90 \mathrm{~min}$ at $4^{\circ} \mathrm{C}$ ) to prepare a sol phase sample to determine mediator concentrations. The second was treated with dithiothreitol to assess total cell numbers and cytospins prepared for total and differential cell counts of squamous cells, neutrophils, eosinophils, macrophages and lymphocytes. ${ }^{12}$ Where relevant, patients were asked to abstain from smoking from waking until sputum collection was complete.

\section{Measurement of mediators}

Mediators were measured using Enzyme Amplified Sensitivity Immunoassay (R\&D Systems, Abingdon, UK) and expressed in molar concentrations. All assays were validated to determine their working range and the variability of mediator measurements both within and between assay plates using methods described previously. ${ }^{12}$

In order to reduce intra-patient variability in biomarkers, the effects of employing a rolling mean were assessed. A 3-day rolling mean was determined for each mediator and cell count in each patient by averaging the results from visits 1,2 and 3 ("rolling mean 3a"), then from visits 2,3 and 4 ("rolling mean 36 "), etc, until the final visit was incorporated into a rolling mean ("rolling mean 3i"). A 5-day rolling mean was also determined for each biomarker in each patient by averaging the results from visits $1-5$ ("rolling mean $5 a$ "), then from visits 2-6 ("rolling mean 5b"), etc, until the final visit ("rolling mean $5 \mathrm{~g} ")$.

\section{Statistical analysis}

Data analysis was performed using SPSS 12.0 for Windows (SPSS, Chicago, Illinois, USA). Normally distributed data are expressed as mean and standard deviations, categorical data as percentages and non-normally distributed data as median and interquartile range (IOR). Non-normally distributed continuous variables (such as mediator concentrations and cell counts) were log transformed to achieve normality and allow calculation of the coefficient of variation (CV). The correlations between logged mediator concentrations and cell counts were evaluated by Pearson's correlation coefficient (PCC).

Sample size calculations were based on both a two-group parallel comparison and a paired (crossover) comparison in clinical trials. A parallel design used the formula:

$$
n=1+2 C\left(\frac{S}{D}\right)^{2}
$$

and a crossover design used the formula:

$$
n=1+C\left(\frac{S}{D}\right)^{2}
$$

where $\mathrm{D}$ was the smallest difference to be detected (a $50 \%$ decrease in mediator concentration or cell count was used as an arbitrary effect size for illustrative purposes) and $\mathrm{S}$ represented the standard deviation of the observations. $\mathrm{C}=7.85$ to provide an $80 \%$ power of detecting a reduction in mean mediator concentration or cell counts at the $5 \%$ level of significance. ${ }^{13}$

\section{RESULTS}

\section{Baseline characteristics}

Fourteen patients were enrolled and their baseline characteristics are summarised in table 1 . The medications being taken by each patient during the study are listed in table E1 in the online supplement. Exacerbations, defined clinically, ${ }^{14}$ were excluded on each visit by review of daily dairy cards, clinical examination, confirmation of unchanged therapy ${ }^{15}$ and weekly spirometry. None of the patients experienced an exacerbation during the study period and there were no significant changes in diary scores or lung function between visits.

\section{Assay variability and sputum characterisation}

In all cases the mediator intra- and inter-assay variability was less than $10 \%$. The median percentage of squamous cells in the samples was $0.6 \%$ (IOR $0-7.9 \%$ ) and the median percentage of viable cells (assessed by trypan blue exclusion) was 83\% (IOR $63-92 \%$ ) which is comparable to that seen with induced sputum. ${ }^{16}$

\section{Intra-patient variability in mediator concentrations and neutrophils}

There was considerable variability in the concentrations of mediators and cells within individual patients over the study period. Figure 1 demonstrates the variability seen for one

Table 1 Baseline characteristics of the study patients

\begin{tabular}{ll}
\hline Characteristic & \\
\hline Age (years) & $65.5(8.5)$ \\
Male (\%) & $6(43 \%)$ \\
Diagnosis (years) & $6.4(5.4)$ \\
$\mathrm{FEV}_{1}$ (I) & $0.89(0.3)$ \\
$\mathrm{FEV}_{1}$ (\% of predicted) & $40(8.3)$ \\
$\mathrm{FVC}(\mathrm{I})$ & $2.28(0.61)$ \\
$\mathrm{FEV} / \mathrm{FVC}$ & $42(11)$ \\
Increase in FEV $_{1}$ following $400 \mu \mathrm{g}$ inhaled salbutamol \\
$\quad \mathrm{ml}$ & $132(77)$ \\
$\quad \%$ predicted & $5(3.3)$ \\
$\mathrm{BMI}\left(\mathrm{kg} / \mathrm{m}^{2}\right)$ & $23.8(4.5)$ \\
Current smokers (\%) & $6(43 \%)$ \\
Pack year history & $45(20.7)$ \\
Taking inhaled steroids at enrolment (\%) & $11(79 \%)$ \\
\hline
\end{tabular}

$\mathrm{FEV}_{1}$, forced expiratory volume in $1 \mathrm{~s}$; FVC, forced vital capacity; BMI, body mass index.

Results are presented as mean (SD) or $\mathrm{n}(\%)$. 
Table E1 The list of medications taken by each patient during the study period

\begin{tabular}{ll}
\hline Patient & Medications \\
\hline 1 & Salbutamol $100 \mathrm{mcg}$ inh bd \\
& Tiotropium $18 \mathrm{mcg}$ inh od \\
& Beclometasone dipropionate \\
& $200 \mathrm{mcg}$ inh bd \\
& Aspirin $75 \mathrm{mg}$ po od
\end{tabular}

2 Salmeterol $50 \mathrm{mcg}$ inh bd Salbutamol $100 \mathrm{mcg}$ inh prn Budesonide $200 \mathrm{mcg}$ inh bd Ipratropium $40 \mathrm{mcg}$ inh bd Theophylline modified release $250 \mathrm{mg}$ po bd

3 Salmeterol $100 \mathrm{mcg}$ inh bd Salbutamol $100 \mathrm{mcg}$ inh bd Ipratropium $40 \mathrm{mcg}$ inh bd

Salmeterol $50 \mathrm{mcg}$ inh bd Salbutamol $100 \mathrm{mcg}$ inh prn Fluticasone propionate $200 \mathrm{mcg}$ inh bd

Fluticasone propionate $100 \mathrm{mcg}$ inh bd

Ranitidine $300 \mathrm{mg}$ po od

4 Seretide $(250 \mathrm{mcg} / 50 \mathrm{mcg})$ inh bd11 Salbutamol $100 \mathrm{mcg}$ inh prn

Salmeterol $50 \mathrm{mcg}$ inh bd 12

Salbutamol $100 \mathrm{mcg}$ inh prn Ipratropium $20 \mathrm{mcg}$ inh bd

Beclometasone dipropionate

$20 \mathrm{mcg}$ inh bd

Paracetamol $1 \mathrm{~g}$ po ODS

Salmeterol $50 \mathrm{mcg}$ inh bd

Salbutamol $100 \mathrm{mcg}$ inh prn

Ipratropium $20 \mathrm{mcg}$ inh qds

Ipratropium $20 \mathrm{mcg}$ inh bd

Fluticasone propionate $250 \mathrm{mcg} 14$

inh bd

Lansoprazole $15 \mathrm{mg}$ po od

Warfarin $3 \mathrm{mg}$ po od (variable

dose)

Furosemide $20 \mathrm{mg}$ po od

Medications taken during the study period. Medications did not change for 8 weeks prior to the study or during the study period.

patient and table E2 (in the online supplement) describes the intra-patient variability for all mediators and sputum neutrophil and macrophage counts for each patient.

The variability in sputum inflammatory markers seen within patients was wide, irrespective of the inflammatory mediator or cell type measured. The median intra-patient CV for each mediator (calculated from each patient's CV) is shown in table 2. This variability was not related to any changes in individual symptoms as recorded in the patients' diary card scores, clinical features, sputum microbiology or lung function (all of which remained stable).

\section{Reducing intra-patient variability}

Table 3 compares the effects of a rolling mean on intra-patient variability for all patients and all mediators (expressed as CVs). When comparing a single mediator within patients, a significant reduction in variability of the raw data (as determined by the CV) was obtained using a 3-day rolling mean in all biomarkers except

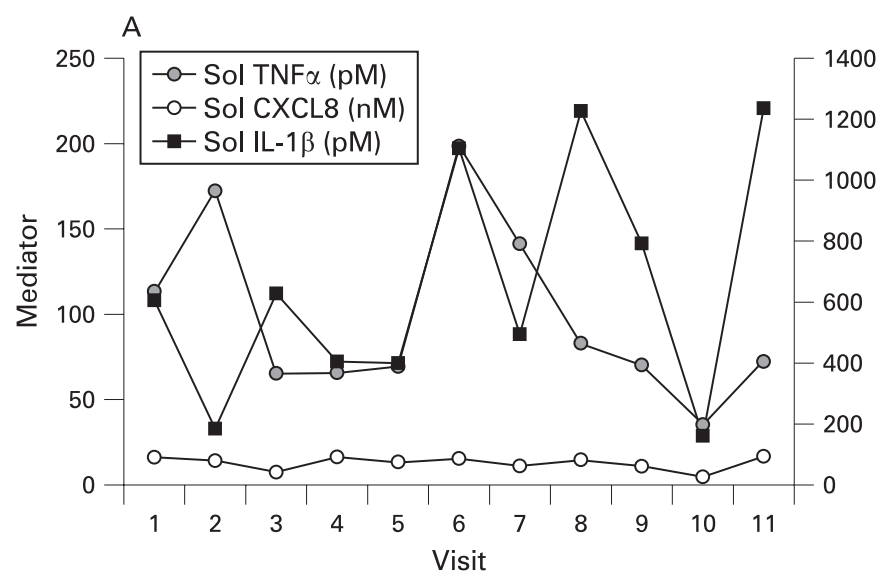

B

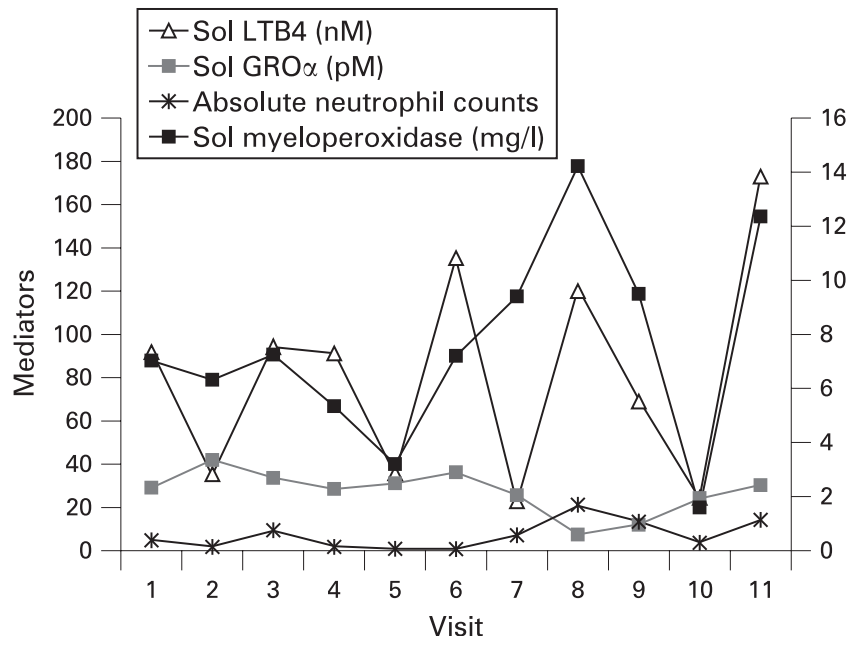

Figure 1 Changes in the concentrations of sputum sol phase mediators for one patient during the study period. Each data point represents the measured concentration of one mediator for a single patient on a single visit (in units as per figure legend). (A) Changes in raw data over 1 month for patient 1 for the sputum sol mediators IL-1 $\beta$, TNF $\alpha$ and CXCL8. IL-1 $\beta$ concentrations are given on the right hand axis, TNF $\alpha$ and CXCL8 concentrations are given on the left hand axis. (B) Changes in raw data over 1 month for patient 1 for the sputum sol phase mediators MPO, LTB4, GRO $\alpha$ and absolute neutrophil counts. MPO concentrations are given on the right hand axis, LTB4, GRO $\alpha$ concentrations and absolute neutrophil counts $\left(10^{6} / \mathrm{ml}\right)$ are given on the left hand axis. IL, interleukin; TNF, tumour necrosis factor; CXCL8, interleukin 8; MPO, myeloperoxidase; LTB4, leucotriene B4; GRO, growth-related oncogene.

for sputum neutrophil counts. A further reduction in variability was seen using a 5-day rolling mean in all biomarkers including sputum neutrophil counts. Figure 2A-C (available online) compares graphically the variability in mediator concentrations and the effect of rolling means for one representative patient.

\section{Inter-patient variability and the effects of a rolling mean}

There was marked variability in inflammatory biomarkers between patients with COPD using data from a single day. Using a 3-day or 5-day rolling means for each patient did not alter the inter-patient variability, which suggests that it relates to individual differences in the degree of airway inflammation.

When all mediators were considered together, the median variability between patients using daily data (expressed as the CV) was 101\% (IOR 90-123\%) and the median variability 
Table E2 The within patient variability in pulmonary inflammatory mediators and cells seen in stable patients with severe COPD over one month

\begin{tabular}{|c|c|c|c|c|c|c|c|c|c|}
\hline Patient & & IL-1ß (pM) & TNF $\alpha$ (pM) & CXCL8 (nM) & MPO (mg/ml) & LTB4 (nM) & $\mathrm{GRO} \alpha(\mathrm{nM})$ & Neutrophils $\left(10^{6} / \mathrm{ml}\right)$ & Macrophages $10^{6} / \mathrm{ml}$ ) \\
\hline \multirow[t]{3}{*}{1} & Median & 606 & 72.2 & 14.27 & 7.2 & 91.2 & 29.1 & 4.8 & 0.09 \\
\hline & IQR & 399-1104 & $66-141$ & $10.9-16.1$ & $5.34-9.5$ & $35-120$ & $24-33$ & $1.8-13.4$ & $0.06-0.17$ \\
\hline & CV & 11 & 11.3 & 15.9 & 32.9 & 16.9 & 16 & 77.3 & 31.8 \\
\hline \multirow[t]{3}{*}{2} & Median & 19.1 & 0.4 & 4.8 & 1.8 & 1.4 & 14.7 & 1.3 & 0.18 \\
\hline & IQR & $9.3-26.6$ & $0.19-0.69$ & $3.85-6.68$ & $1.24-1.8$ & $0.85-1.96$ & $12-20.4$ & $0.4-1.95$ & $0.14-0.34$ \\
\hline & CV & 19.6 & 87 & 25.4 & 162.5 & 194 & 9.6 & 471 & 37.1 \\
\hline \multirow[t]{3}{*}{3} & Median & 5.8 & 0.3 & 1.4 & 1.7 & 5.9 & 18.1 & 0.9 & 0.12 \\
\hline & IQR & $3.4-6.6$ & $0.2-0.6$ & $1.2-1.5$ & $1.4-1.9$ & $5-6.5$ & $16.6-19.7$ & $0.7-1.4$ & $0.07-0.13$ \\
\hline & CV & 30.3 & 45.3 & 85 & 61.2 & 22.2 & 12.3 & 804 & 44 \\
\hline \multirow[t]{3}{*}{4} & Median & 501 & 52.2 & 24.4 & 2.41 & 28 & 16.8 & 5.35 & 0.2 \\
\hline & IQR & $417-865$ & $48.5-68.8$ & $19.8-27.5$ & $1.6-4.5$ & $20.5-42$ & $14.7-18.7$ & $2.5-7.4$ & $0.13-0.42$ \\
\hline & CV & 8.3 & 6.6 & 20.7 & 84.3 & 13.5 & 9.5 & 44.9 & 51.7 \\
\hline \multirow[t]{3}{*}{5} & Median & 697 & 74.6 & 26 & 4.13 & 10.23 & 3.16 & 6.25 & 0.4 \\
\hline & IQR & $375-775$ & 33.2-105 & $18.4-43$ & $2-7.2$ & $7.4-23.4$ & $1.5-3.8$ & $5.2-25.9$ & $0.26-0.81$ \\
\hline & CV & 10 & 31 & 13.9 & 74.3 & 25.1 & 96.8 & 44.8 & 81.7 \\
\hline \multirow[t]{3}{*}{6} & Median & 120.2 & 4.32 & 5.37 & 4.27 & 11.17 & 12.3 & 3.4 & 0.27 \\
\hline & IQR & $65.9-343$ & $0.4-42$ & $2.5-6.9$ & $3.4-6.4$ & $2.2-17.6$ & $10.2-16.5$ & $2.2-5.9$ & $0.16-0.3$ \\
\hline & CV & 21.2 & 159 & 44.3 & 35.4 & 47.9 & 18.5 & 38.7 & 30.4 \\
\hline \multirow[t]{3}{*}{7} & Median & 606 & 253 & 40.1 & 5.79 & 49.04 & 12.3 & 18.1 & 0.46 \\
\hline & IQR & 504-1128 & $212-301$ & $27.7-61.4$ & 3.4-13.8 & $21.7-75.7$ & $10.6-21.2$ & $12.7-24.9$ & $0.31-0.73$ \\
\hline & CV & 12 & 5.6 & 12.5 & 59.2 & 21.9 & 16.4 & 17.3 & 98.3 \\
\hline \multirow[t]{3}{*}{8} & Median & 5.1 & 0.1 & 0.33 & 1.15 & 0.95 & 4.87 & 0.4 & 0.03 \\
\hline & IQR & $3.1-5.9$ & $0.03-0.14$ & $0.24-0.41$ & $1.04-1.43$ & $0.6-1.5$ & $3.5-6.4$ & $0.3-0.8$ & $0.03-0.06$ \\
\hline & CV & 39.8 & 29.8 & 29 & 224 & 1299 & 189 & 92.5 & 31.3 \\
\hline \multirow[t]{3}{*}{9} & Median & 9.26 & 0.25 & 1.04 & 1.93 & 0.49 & 8.12 & 0.4 & 0.33 \\
\hline & IOR & $3.5-43.4$ & $0.02-1.1$ & $0.5-2.6$ & $1.1-2.6$ & $0.32-0.7$ & $4.7-9.8$ & $0.2-1.6$ & $0.17-0.65$ \\
\hline & CV & 55.5 & 113 & 633 & 70.5 & 159.4 & 20.6 & 236.5 & 86.7 \\
\hline \multirow[t]{3}{*}{10} & Median & 156.9 & 5.25 & 2.11 & 2.03 & 10.81 & 5.04 & 2.15 & 0.7 \\
\hline & IOR & 88-417 & 3-10.4 & $1.7-3$ & $1.9-2.4$ & 7.1-15.1 & 3.9-5.3 & $0.95-12.6$ & $0.31-2.07$ \\
\hline & CV & 19 & 37.4 & 49.2 & 22.7 & 27.9 & 11.6 & 181 & 152.4 \\
\hline \multirow[t]{3}{*}{11} & Median & 10.6 & 0.06 & 0.11 & 1.38 & 6.74 & 0.3 & 1.65 & 0.35 \\
\hline & IOR & 7.5-11.8 & $0.04-0.2$ & $0.06-0.14$ & $1.2-2.6$ & $3.8-11.7$ & $0.1-0.4$ & $1.1-2.2$ & $0.09-0.68$ \\
\hline & CV & 11.4 & 29.2 & 24.3 & 85.7 & 32 & 54.1 & 92.4 & 104.7 \\
\hline \multirow[t]{3}{*}{12} & Median & 31 & 4.89 & 3.7 & 0.88 & 3.07 & 24 & 5.1 & 3.31 \\
\hline & IQR & $18-41.9$ & $2.7-10$ & $2.8-4.3$ & $0.6-1.1$ & $2.3-7.6$ & $21.4-28.4$ & $4.1-6.7$ & $2.3-3.9$ \\
\hline & CV & 16.3 & 87 & 32.7 & 186.7 & 111.2 & 4.4 & 20 & 44.5 \\
\hline \multirow[t]{3}{*}{13} & Median & 13.8 & 0.19 & 2.05 & 1.28 & 1.77 & 16.8 & 1.8 & 1.92 \\
\hline & IQR & $6.7-30.8$ & $0.1-0.3$ & $1.3-3.7$ & $1-1.4$ & $0.9-1.8$ & 7.8-21.8 & $0.8-5.3$ & $0.28-2.56$ \\
\hline & CV & 31.2 & 29.3 & 73.8 & 107.9 & 111.8 & 4.4 & 178 & 1100 \\
\hline \multirow[t]{3}{*}{14} & Median & 3.12 & 0.16 & 2.03 & 0.78 & 0.49 & 19.7 & 2.65 & 1.12 \\
\hline & IOR & $2-4.9$ & $0.1-0.2$ & $1.4-2.6$ & $0.3-0.9$ & $0.2-1.6$ & $18.4-22$ & $2.2-5.2$ & $1-1.53$ \\
\hline & CV & 46.9 & 13.4 & 60.1 & 129.5 & 180 & 5.5 & 50.1 & 159.7 \\
\hline
\end{tabular}

The median biomarker concentration (with corresponding inter-quartile range) is given for each patient. The co-efficient of variation (CV) for each patient was determined from log transformed data and is expressed as a percentage.

between patients using the first 5-day rolling mean was only slightly reduced to $91 \%$ (IOR 73-115\%) (table 4).

\section{Determining the sample size required to power interventional studies}

Using a crossover design, the number of patients needed to confirm a 50\% reduction in sputum neutrophil counts with $80 \%$ power and at the $5 \%$ significance level using a single data point per patient would be 72 . However, if a 3-day mean is used, the number needed to confirm the same reduction would be 23 , and 20 with a 5 -day mean. For a parallel design, the number needed to confirm a $50 \%$ reduction in sputum neutrophil counts using a single data point would be 140 (70 per group), which would be reduced to 106 and 103 using a 3-day or 5-day mean, respectively.

Table E3 (available online) summarises the mean (SE) number of patients required to detect similar changes in other mediators

Table 2 Median intra-patient coefficient of variation (CV) for each mediator

\begin{tabular}{lll}
\hline Mediator & CV (\%) & IQR \\
\hline IL-1 $\beta(\mathrm{pM})$ & 19.4 & $11-33$ \\
TNF $\alpha$ (pM) & 30.3 & $13-88$ \\
LTB4 (nM) & 39.9 & $22-165$ \\
CXCL8 (nM) & 30.8 & $19-63$ \\
GRO $\alpha(\mathrm{nM})$ & 16.2 & $10-29$ \\
Absolute neutrophil count $\left(10^{6} / \mathrm{ml}\right)$ & 77.3 & $42-180$ \\
Absolute macrophage count $\left(10^{6} / \mathrm{ml}\right)$ & 74.2 & $41-102$ \\
MPO (mg/ml) & 79.3 & $53-138$ \\
\hline
\end{tabular}

The median intra-patient CV is derived from each individual patient's CV. Each patient's mediator-specific CV was calculated using data from 11 sequential visits.

IL-1 $\beta$, interleukin $1 \beta$; TNF $\alpha$, tumour necrosis factor $\alpha$; LTB4, leucotriene B4; CXCL8, interleukin 8; $\mathrm{GRO} \alpha$, growth-related oncogene $\alpha$; MPO, myeloperoxidase; IQR,

interquartile range. 
Table 3 Comparison of the median intra-patient coefficient of variation (CV) for each mediator using daily data, a 3-day rolling mean and a 5-day rolling mean

\begin{tabular}{|c|c|c|c|c|c|c|c|c|}
\hline & IL-1及 (pM) & TNF $\alpha(p M)$ & CXCL8 (nM) & MPO (mg/l) & LTB4 (nM) & GRO $\alpha$ (pM) & $\begin{array}{l}\text { Sputum } \\
\text { neutrophils } \\
\left(10^{6} / \mathrm{ml}\right)\end{array}$ & $\begin{array}{l}\text { Sputum } \\
\text { macrophages } \\
\left(10^{6} / \mathrm{ml}\right)\end{array}$ \\
\hline \multicolumn{9}{|l|}{ Raw data } \\
\hline $\mathrm{IQR}$ & $11-33$ & $13-88$ & $19-63$ & 53-138 & $22-165$ & $10-29$ & $42-180$ & $41-102$ \\
\hline \multicolumn{9}{|l|}{ 3-day rolling mean } \\
\hline \multicolumn{9}{|l|}{ 5-day rolling mean } \\
\hline Median CV (\%) & $6.9^{*} \dagger$ & $12.2^{*} \dagger$ & $9.5^{*} \dagger$ & $22^{*} \dagger$ & $13.8^{*} \dagger$ & $4.1^{*} \dagger$ & $13.4^{*} \dagger$ & $20^{*}$ \\
\hline IOR & $4-9$ & $2-37$ & $4-20$ & $13-39$ & $4-53$ & $2.6-6.8$ & 8-124 & $13-32$ \\
\hline
\end{tabular}

The median coefficient of variation (CV) has been derived from the marker-specific CV from each patient. Differences in CVs were assessed using the Friedman matched samples test and the Wilcoxon matched pairs signed rank test.

IL-1 $\beta$, interleukin 1 $\beta$; TNF $\alpha$, tumour necrosis factor $\alpha$; CXCL8, interleukin 8; MP0, myeloperoxidase; LTB4, leucotriene B4; GR0 $\alpha$, growth-related oncogene $\alpha$; IQR, interquartile range.

${ }^{*}$ Significant reduction in mean CV from raw data $(p<0.05)$.

$\uparrow$ Significant reduction in mean CV from 3-day rolling mean $(p<0.05)$.

when a single sample is collected or when the mean of three or five consecutive samples is used for power calculations.

\section{Relationship between sol phase inflammatory mediators and sputum cell counts}

The strength of the correlations between mediators and cells (and the significance of these correlations) increased as more data points were used for each patient. Figure 3A-C (available online) demonstrates the correlations seen between sol phase LTB4 and sputum neutrophil counts when the first day's data were used for each patient (fig 3A) compared with the mean of the first 3 days (fig $3 \mathrm{~B}$ ) or all 11 days (fig $3 \mathrm{C}$ ). Figure $4 \mathrm{~A}-\mathrm{C}$ (available online) demonstrates the correlations seen between IL-1 $\beta$ and the absolute sputum neutrophil count, TNF $\alpha$ and CXCL8, respectively, using the mean value for all 11 samples for each patient.

Tables E4 and E5 (available online) describe the correlations seen between all mediators and neutrophils using a similar approach. In general there was an increase in the correlation coefficient using the mean of 3 days' data compared with 1 day's data (mean difference in Pearson's correlation coefficient between 1 day's data and the mean of 3 days' data $=0.11(95 \%$ confidence interval 0.04 to 0.18 ), $p=0.003$ ), but there was no further increase in the strength of the correlation using the mean of more data points.

All biomarkers measured showed inter-relationships with each other of varying significance (see table $\mathrm{E} 4$ in the online supplement) with the exception of GRO $\alpha$ which showed no correlation with neutrophils or any other mediator measured in sputum, apart from CXCL8.

\section{Relationship between sol phase inflammatory mediators, cell counts and disease}

Correlations were seen between inflammatory mediators and markers of disease but, as with the inter-relationships between mediators, the strength of the correlation (and the significance value) increased as more data points were used for each patient. Using the first day's data for each patient, only IL-1 $\beta$ correlated with body mass index (BMI; $r=-0.5, p=0.03$ ). Using the mean of the first 3 days for each patient, significant correlations were seen between BMI and IL-1 $\beta(r=-0.5, p=0.02)$ and
TNF $\alpha(r=-0.48, p=0.03)$. However, using the mean of 11 data points per person, significant correlations were present between BMI and IL-1 $\beta(r=-0.41, p=0.05)$, TNF $\alpha(r=0.4$, $p=0.05)$ and LTB4 $(r=-0.51, p=0.03)$; smoking history and sputum neutrophils $(r=-0.61, p=0.008)$ and sputum macrophages $(r=0.46, p=0.05)$; and forced expiratory volume in $1 \mathrm{~s}$ $\left(\mathrm{FEV}_{1}\right)$ and $\mathrm{TNF} \alpha(\mathrm{r}=-0.45, \mathrm{p}=0.04)$ and sputum neutrophils $(\mathrm{r}=-0.6, \mathrm{p}=0.01)$. Figure $5 \mathrm{~A}-\mathrm{C}$ (available online) summarises the correlation between $\mathrm{FEV}_{1}$ and sputum neutrophil counts for a single sample (day 1) for each patient (fig $5 \mathrm{~A}$ ) compared with the mean for the first 3 days (fig $5 \mathrm{~B}$ ) or 11 days (fig $5 \mathrm{C}$ ).

\section{DISCUSSION}

In this well characterised group of patients with GOLD stage III COPD and chronic bronchitis, marked variability in inflammatory mediators and cells was found, both between patients and within each patient over the course of a 4-week period. Given the heterogeneous nature of COPD, it is perhaps unsurprising that inflammatory biomarkers vary between individuals and, indeed, this finding is in agreement with a wealth of previously published data. ${ }^{17} 18$

The variability of the raw data within individuals was also marked, even in samples taken on consecutive days, and the fluctuations did not relate to changes in symptom scores, clinical findings or changes in $\mathrm{FEV}_{1}$ (all of which remained stable). It is likely that the variability reflects changes in sampling methodology or sputum humidification over the study period rather than individual patients showing wide fluctuations in the daily inflammatory load of the lungs without this impacting on daily symptoms. It may be that only when changes in lung inflammatory load are sustained at a higher magnitude over consecutive days does it relates to changes in clinical status. This relationship has been demonstrated in patients with prednisone-dependent asthma where clinical indices deteriorate much later than the inflammatory changes in sputum. ${ }^{19}$

Sampling techniques vary between studies of inflammation in COPD, but the intra- and inter-patient variability of measured mediators is unknown for most methodologies. The variability of sequential bronchial biopsies appears significant despite this technique having the advantage of directly sampling airway 

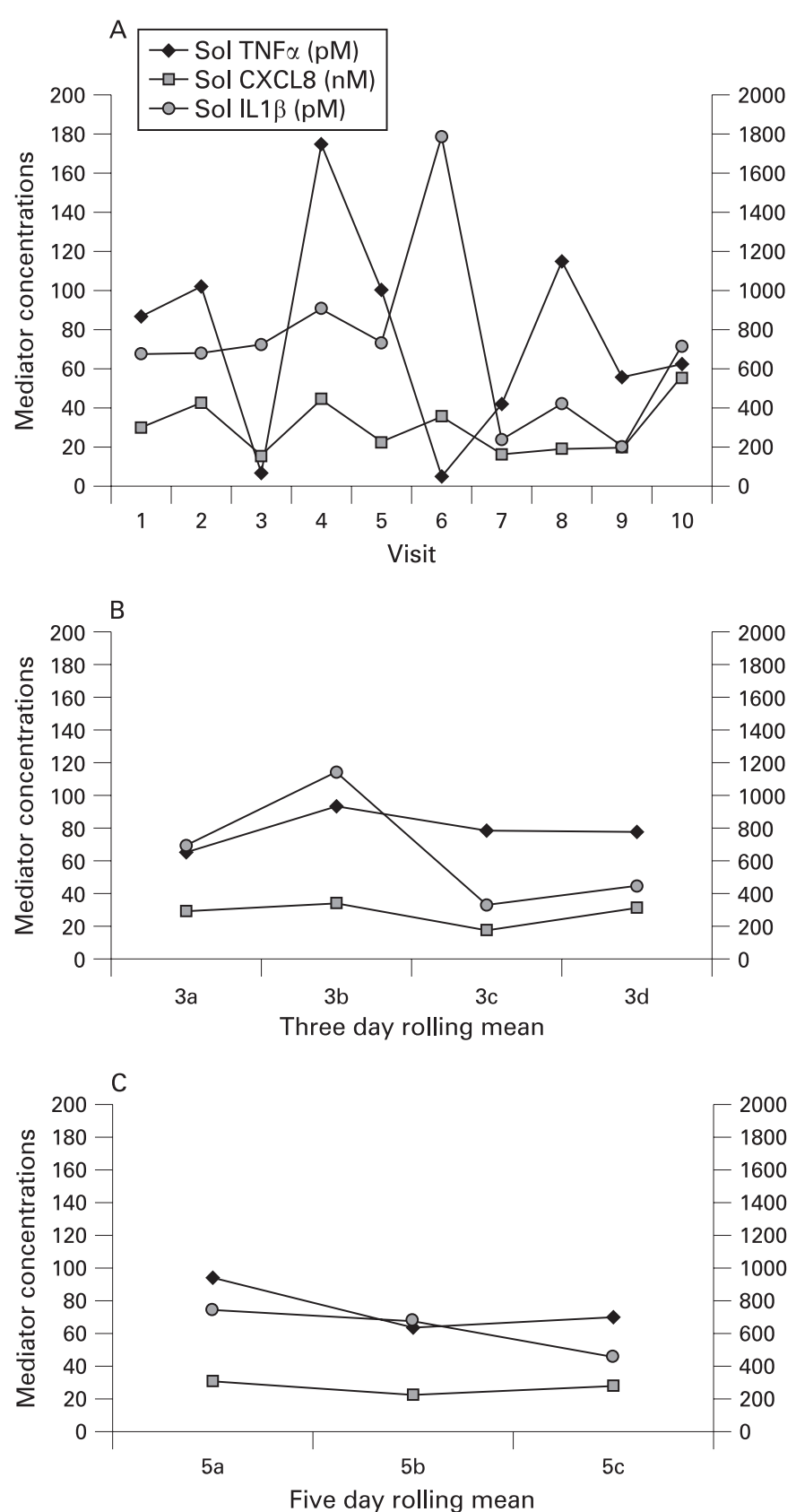

Figure 2 Comparison of intra-patient variability in three mediators using either data from 10 sequential visits or a rolling mean. For all figures, concentrations of interleukin $1 \beta$ (IL-1 $1 \beta$ ) are given on the right-hand axis and concentrations of tumour necrosis factor $\alpha$ (TNF $\alpha$ ) and interleukin 8 (CXCL8) are given on the left-hand axis. (A) Changes in raw data over 1 month for a representative patient (patient 5 ) for the sputum sol phase mediators IL-1 $\beta$, TNF $\alpha$ and CXCL8. Data points represent the measured concentration of one mediator for a single patient on a single visit (in units as per figure legend). (B) Changes in mediators over 1 month for patient 5 using a 3-day rolling mean. Data points represent the mean measured concentration of one mediator for 3 consecutive days for a single patient. A 3-day rolling mean was determined for each mediator and cell count in this patient by averaging the results from visits 1, 2 and 3 (rolling mean " $3 a^{\prime \prime}$ on $x$ axis), then from visits 2,3 and 4 (rolling mean " $3 b^{\prime \prime}$ ) etc, until the final three visits were incorporated into a rolling mean (" $\left.3 i^{\prime \prime}\right)$. (C) Changes in mediators over 1 month for patient 5 using a 5-day rolling mean. Data points represent the mean measured concentration of one mediator for 5 consecutive days for a single patient. A 5-day rolling mean was determined for each biomarker in this patient by averaging the results from visits 1-5 (rolling mean " $5 \mathrm{a}$ " on $x$ axis), then from visits 2-6 (rolling mean " $5 b^{\prime}$ "), etc, until the final visit ("rolling mean $5 \mathrm{~g}$ ). tissue. $^{20}$ To date, one study has provided data regarding the reproducibility of induced sputum: three samples taken at 4weekly intervals showed no significant differences in neutrophil counts or CXCL8 concentrations in 12 patients with mild to moderate COPD. ${ }^{21}$ The concentration of mediators in exhaled breath condensate (EBC) is often at levels close to the lower limit of detection (and often below the lower limit of quantification) for most assays, making accurate measurements difficult. ${ }^{22}$ There is high variability in repeated measurements of EBC inflammatory indices, ${ }^{23}$ which is likely to be dependent upon difficulty both in quantification as well as the dilution caused by water vapour. Bronchoalveolar lavage (BAL) fluid samples are also complicated by dilution from the lavage which is operator-dependent, variable and for which no correction factor has been determined. ${ }^{8}$ Furthermore, the variability of biomarkers using BAL fluid is currently unknown because of practicalities of repeated sampling.

Spontaneous sputum collection is non-invasive and has no inflammatory sequelae to limit sequential sampling. Furthermore, spontaneous sputum samples are the only medium where an artificial dilution factor is absent. ${ }^{84}$ However, there is still an inherent physiological dilution present in all lung secretions which will have an impact on the ability to perform accurate serial measurements.

Sputum is a mixture of lower airway and oropharyngeal secretions. Lower airway secretions are affected by exudation of plasma-derived proteins into the airway lumen ${ }^{25}$ which occurs both when the epithelial mucosa is damaged ${ }^{26}$ and intact, both structurally and functionally, ${ }^{27}$ and presents a dilutional factor inherent in all sampling methodologies.

Oropharyngeal contamination can be reduced by patient education and confirmed by the percentage of squamous cells in the sample, which should typically be less than 10\%. In our study, squamous cells accounted for less than $1 \%$ of cells seen in the samples, suggesting that oropharyngeal contamination was low. Although we took the precaution of asking patients to rinse their mouths prior to expectoration, the rinse itself or any remaining oropharyngeal secretions could still dilute the sputum samples. Indeed, this could explain some of the intrapatient variability seen day to day, and similar effects could influence the between-patient variability.

If mediator and cell values were overwhelmingly influenced by dilution, it would be predicted that mediator concentrations between patients would correlate well, as dilute samples would have low measured concentrations of mediators and concentrated samples would have high measured concentrations of mediators, even if all patients were in the same inflammatory state and mediator secretion was identical. The data for GRO $\alpha$, however, suggest that this is not the case. In our study GRO $\alpha$ failed to correlate with any other mediator except CXCL8. This suggests, firstly, that the remaining correlations reflect different inflammatory states per patient and, secondly, that GRO $\alpha$ does not reflect inflammatory differences between patients or the neutrophil content of airway secretions. GRO $\alpha$ may be less important in the development or progression of COPD than other mediators. It is possible that GRO $\alpha$ has a different spectrum of activity than previously suspected, ${ }^{28}$ or that GRO $\alpha$ is maximally expressed in COPD patients with chronic bronchitis irrespective of the degree of inflammation. ${ }^{29}$ However, the fact that GRO $\alpha$ does not correlate with other biomarkers provides sound evidence that the relationships seen between other mediators are not purely dilutional in nature. Furthermore, the correlations with systemic markers of disease $\left(\mathrm{BMI}\right.$ and $\mathrm{FEV}_{1}$ ) and the use of repeated sampling (when any 
Table 4 Comparison of the inter-patient coefficient of variation (CV) for each mediator using raw data or data manipulated using a 5-day rolling mean

\begin{tabular}{|c|c|c|c|c|c|c|c|c|c|}
\hline & IL-1及 (pM) & TNF $\alpha$ (pM) & CXCL8 (nM) & MPO (mg/ml) & LTB4 (nM) & $\mathrm{GRO} \alpha(\mathrm{nM})$ & $\begin{array}{l}\text { Sputum } \\
\text { macrophages } \\
\left(10^{6} / \mathrm{ml}\right)\end{array}$ & $\begin{array}{l}\text { Sputum } \\
\text { neutrophils } \\
\left(10^{6} / \mathrm{ml}\right)\end{array}$ & Median CV (IOR) \\
\hline Median & 43.3 & 2.07 & 3.6 & 1.8 & 6.1 & 12.3 & 0.29 & 2.65 & \\
\hline $\begin{array}{l}\text { CV calculated from } \\
\text { raw data }\end{array}$ & 53.5 & 407.8 & 145.4 & 102 & 99.8 & 60.9 & 100 & 115.4 & $101 \%(90-123)$ \\
\hline $\begin{array}{l}\text { CV calculated using } \\
\text { 5-day rolling mean }\end{array}$ & 52.15 & 234.6 & 131 & 92.15 & 78.2 & 58.5 & 110 & 89.4 & $91 \%(73-115)$ \\
\hline
\end{tabular}

The median biomarker concentration (and IQR) is calculated from all measurements for all patients. In order to calculate the inter-patient CVs, the mean logged concentrations were calculated for each biomarker in each patient (either using daily data or data from the first 5-day rolling mean).

IL-1 $\beta$, interleukin 1 $\beta$; TNF $\alpha$, tumour necrosis factor $\alpha$; CXCL8, interleukin 8; MPO, myeloperoxidase; LTB4, leucotriene B4; GR0 $\alpha$, growth-related oncogene $\alpha$; IOR, interquartile range.

variable dilutional factors would be minimised) also makes this explanation unlikely.

We reassessed marker variability within patients by the use of a rolling mean. This technique requires multiple data points in order to overcome fluctuations due to variable sample dilution. A 5-day rolling mean had the optimal effect on intra-patient variability. However, a 3-day rolling mean also reduced intrapatient variability and was able to demonstrate most of the key relationships between mediators. This supports its use as a technique for studying real changes in inflammation in interventional studies. Two 3-day collections of spontaneous sputum (pre- and post-intervention) in each patient would provide a sound basis for interpreting inflammatory changes following treatment.

Simple power calculations were undertaken to assess the effect of single or multiple data points on sample size in a crossover or parallel interventional study design. In a putative trial where a single uncorrected data point is taken for each patient both before and after intervention, our calculations suggest that fewer patients would be needed to see a $50 \%$ reduction in mediators and cells using spontaneous sputum than would be needed to detect the same reduction in mediatorpositive cells in bronchial biopsies. ${ }^{30}$ The numbers needed can be reduced dramatically by using three data points, with a small further reduction with five data points. These results were not altered if data from three separate days were used (eg, days 123, 456,789 , etc) compared with overlapping days (eg, days 123 , $234,345)$ which could be influenced by repeated inclusion of a single day.

The wide inter-patient variability is determined from a relatively small cohort of patients. It is possible that others may have inflammation vastly outside the range documented here which would affect the power calculations for a parallel study. However, the single-day data are consistent with stable state results in our previous larger studies of over 100 patients with a wide range of $\mathrm{FEV}_{1},{ }^{473135}$ suggesting that the current data are representative.

By choosing spontaneous sputum, we limited our recruitment to patients with chronic bronchitis. Although there remains some controversy as to the importance of sputum production in COPD, a body of evidence is emerging that suggests that chronic bronchitis may be a predictor of mortality and morbidity independent of $\mathrm{FEV}_{1}$. Previous work has concluded that the inflammatory burden is higher in patients with chronic bronchitis than in matched patients without chronic bronchitis. ${ }^{31}$ Furthermore, chronic mucus hypersecretion is consistently associated with both an excess decline in $\mathrm{FEV}_{1}$ and an increased risk of subsequent hospitalisation because of COPD, ${ }^{32}$ mucus hypersecretion is associated with death from respiratory infections. ${ }^{33}$ Given the importance of this symptom in COPD and its relationship with inflammation, it is important to understand the relationships between inflammatory mediators in this group of patients. Studying spontaneous sputum samples prevents comparison with healthy controls, which is a limitation of the current study. However, it has been established that the mediators and cells measured in the current study are raised in patients with COPD compared with healthy controls in studies using induced sputum..$^{5-7}$ Furthermore, the aims of the current study were to document the variability of measured mediators and their inter-relationships in spontaneous sputum samples from patients with COPD and chronic bronchitis. A further limitation is that effective

Table E3 A comparison of the numbers needed in a cross-over study design when one day's data, the mean of three days' data or the mean of five days' data are used for calculations

\begin{tabular}{|c|c|c|c|c|c|c|c|c|c|}
\hline & & IL-1ß & TNF $\alpha$ & CXCL8 & MPO & LTB4 & GRO $\alpha$ & $\begin{array}{l}\text { Absolute } \\
\text { macrophage counts }\end{array}$ & $\begin{array}{l}\text { Absolute } \\
\text { neutrophil counts }\end{array}$ \\
\hline 1 days data & $\begin{array}{l}\text { Mean number } \\
\text { of patients }\end{array}$ & 10 & 330 & 61 & 62 & 41 & 20 & 52 & 72 \\
\hline \multirow[t]{2}{*}{3 days data } & $\begin{array}{l}\text { Mean number } \\
\text { of patients }\end{array}$ & 2 & 23 & 7 & 16 & 7 & 5 & 12 & 23 \\
\hline & SEM & 0.73 & 9.08 & 1.93 & 4.01 & 2.13 & 1.94 & 1.7 & 6.69 \\
\hline 5 days data & SEM & 0.07 & 3.12 & 0.30 & 1.49 & 0.45 & 1.34 & 0.6 & 2.25 \\
\hline
\end{tabular}

Numbers required to provide an $80 \%$ chance of detecting a $50 \%$ decrease in mediators or cells at the $5 \%$ level of significance. For 1 day's data, power calculations were performed for each mediator on each visit, and the mean of this is presented (with the standard error of the mean (SEM). For three days' data; power calculations were performed on the first three days (visit 1 to 3), then the next three days (visit 2 to 4 ) until visit 9-11. These were used to calculate the mean number of patients required. For five days' data; power calculations were performed on the first five days (visit 1 to 5 ), then the second five days (visit 2 to 6 ) until visit 7 to 11 . These were used to calculate the mean number of patients required. 

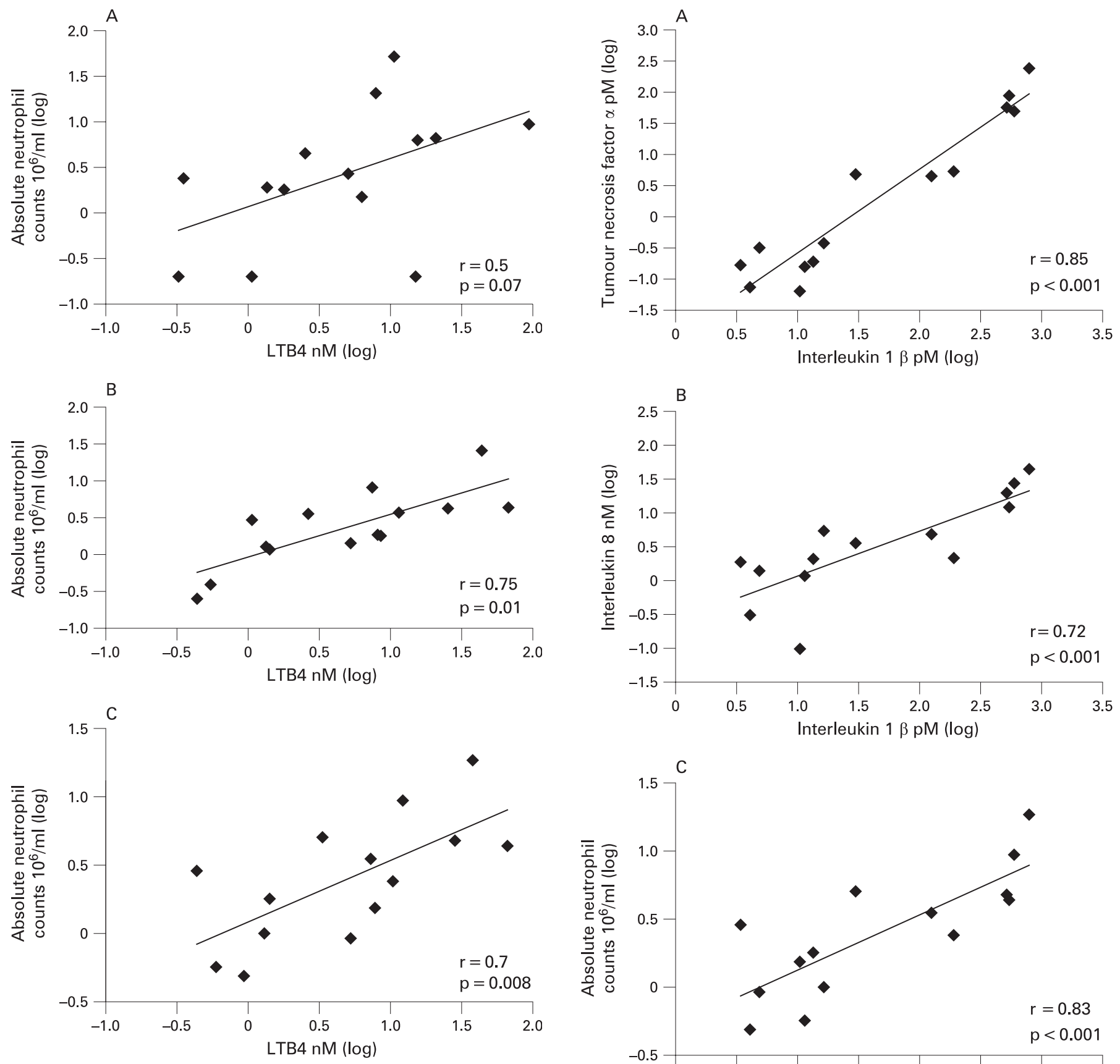

Figure 3 Relationship between sputum sol leucotriene B4 (LTB4) and absolute sputum neutrophil counts using $(A)$ the first day's data for each patient, $(B)$ the mean of the first 3 days' data or $(C)$ the mean of 11 sequential days. In all graphs the data have been log-transformed and the correlation is described using Pearson's correlation coefficient $(r)$ together with the significance of the relationships (p). (A) Data points represent the sputum neutrophil count and sol phase LTB4 concentration for each patient on the first visit. (B) Data are shown for individuals using the mean of the first three samples. (C) Data are shown for individuals using the mean of all 11 samples.

anti-inflammatory interventions may reduce the ability of the subject to produce spontaneous samples, but this in itself would be proof of efficacy and would be likely to reflect a major reduction in inflammation. ${ }^{31}$

The current study demonstrated clear inter-relationships between most of the measured inflammatory mediators which were enhanced by using the mean mediator concentration for

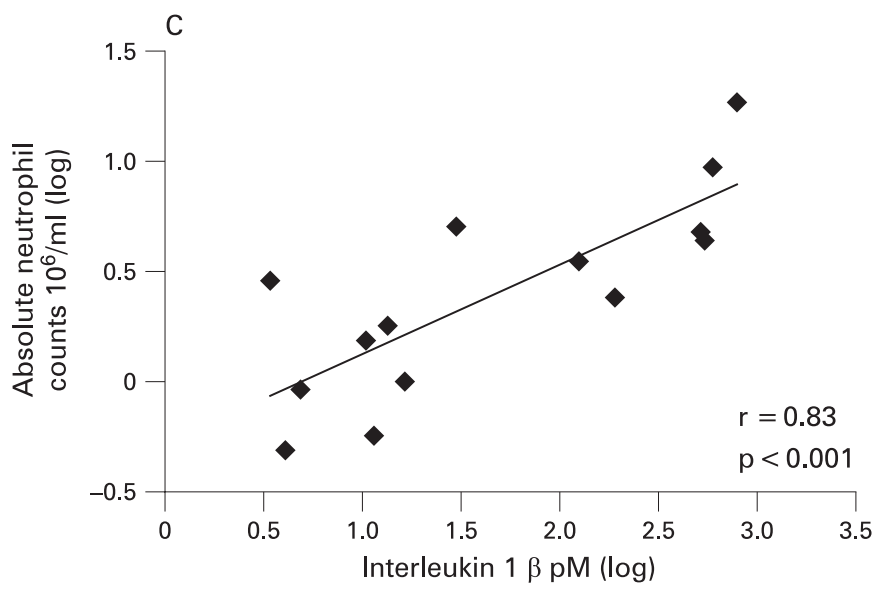

Figure 4 Relationship between sputum sol phase interleukin $1 \beta$ (IL-1 $\beta$ ) and (A) tumour necrosis factor $\alpha$ (TNF $\alpha)$ (B) interleukin 8 (CXCL8) and (C) absolute sputum neutrophil counts. In all graphs the data have been log-transformed. Each point represents the mean of 11 sequential samples for each patient. The correlation is described using Pearson's correlation coefficient $(r)$ together with the significance of the relationships (p).

each patient. Previous studies have reported indirect evidence that some biomarkers may be involved in the pathogenesis of COPD, including the presence of higher concentrations of mediators in disease compared with matched controls and the increases seen during exacerbations. ${ }^{5} 1728303435$ This study is the first to describe the relationships seen between several biomarkers and the strength of these correlations in lung secretions. IL-1 $\beta$ and TNF $\alpha$, in particular, correlated strongly 
Table E4 Correlations between mediators

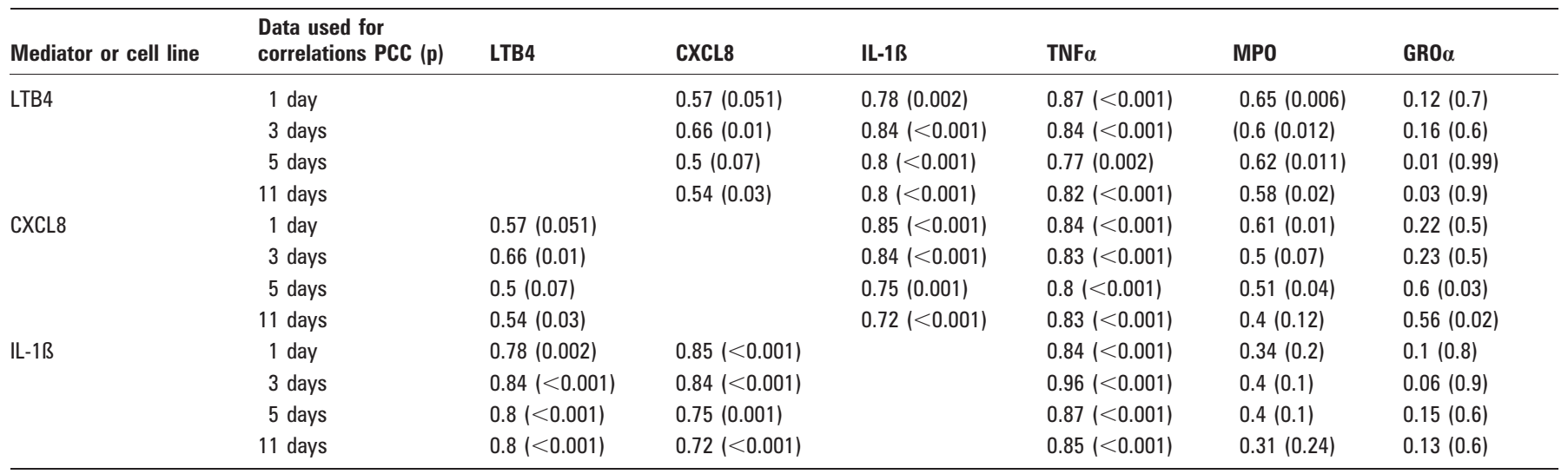

Data describes the relationships between mediators and cell counts when one days data is used (here, the first day), or the mean of the first 3,5 or all 11 days' data. Relationships are expressed as Pearsons Correlation Co-efficient (PCC) and $p$ value.

with all the other measured biomarkers (with the exception of GRO $\alpha$ ) and neutrophils, indicating an intimate relationship with inflammation.

Using mean results for each patient, this study also demonstrated clear relationships between inflammatory biomarkers and other markers of disease including the $\mathrm{FEV}_{1}$ (in litres), smoking history and BMI. Many mediators have been found to be raised in COPD, but it is unlikely that all will be central to the pathogenesis of the disease. $\mathrm{FEV}_{1}$ is the most consistent single predictor of survival and quality of life in $\mathrm{COPD},{ }^{36}$ and the relationships described between $\mathrm{TNF} \alpha$, absolute sputum neutrophil and macrophage counts and both $\mathrm{FEV}_{1}$ and smoking history is highly suggestive that these cells and TNF $\alpha$ are of paramount importance in the pathogenesis of airflow obstruction. Indeed, recent studies suggest that TNF $\alpha$ is associated with the development of emphysema, ${ }^{37}$ and there is a wealth of data supporting the central role of macrophage and neutrophil proteinases in COPD. ${ }^{38}$ It is recognised that weight loss and low body weight are common in COPD, and that low body weight is associated with increased mortality independent of lung function. ${ }^{39}{ }^{40}$ Further studies have suggested that loss of muscle mass is the most important component of weight loss in COPD, and it is this which affects patients functionally. ${ }^{41}$ In the current study, IL-1 $\beta$, TNF $\alpha$ and LTB4 correlated negatively with BMI, supporting the hypothesis that an increase in lung inflammation is associated with a lower body weight. Previous studies have linked a low BMI to systemic inflammation, ${ }^{42}$ but this is the first study to describe the relationship between multiple biomarkers measured in sputum and BMI.
This again provides evidence that these biomarkers may be of importance in COPD and its associated systemic morbidity and supports the concept that wide inter-patient variability is a true finding of inflammatory differences between patients.

Serial measurement of biomarkers enabled us to study their relationships using either 1 day's data or the mean of data from $3,5,7$ or 11 days for each patient. Given the variability of the raw data, it is perhaps unsurprising that correlations were not always present when 1 day's data were examined, although there was still a significant correlation between some mediators (see tables E4 and E5 in the online supplement). However, in general, using the mean of 3 days' data demonstrated the same relationships and provided the same strength of correlations as using the mean of 11 days' data. This is of importance as it has implications for studies designed to assess the relationships between biomarkers and, perhaps more importantly, biomarkers and clinical measures or outcomes. We have shown that potentially important relationships can be missed if only one data point is used, and that the use of at least three data points increases the likelihood of identifying these relationships while the addition of further data points continues to reduce withinpatient variability.

In conclusion, this study documents the variability in mediator concentration both between and within patients with stable severe COPD. Most of this variability is likely to be due to dilution effects, and intra-patient variability is reduced significantly by sequential biomarker measurement which minimises this variation irrespective of alterations in the inflammation signal. This technique would therefore be ideal

Table E5 Correlations between cells and mediators

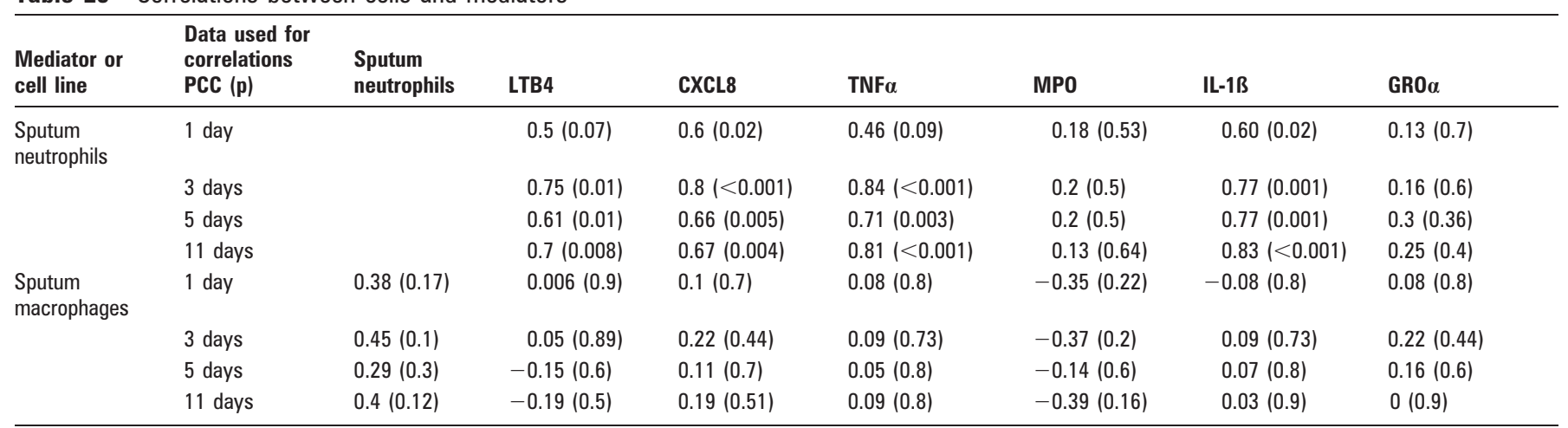

Data describes the relationships between mediators and cell counts when one days data is used (here, the first day), or the mean of the first 3,5 or all 11 days' data. Relationships are expressed as Pearsons Correlation Co-efficient (PCC) and $p$ value. 

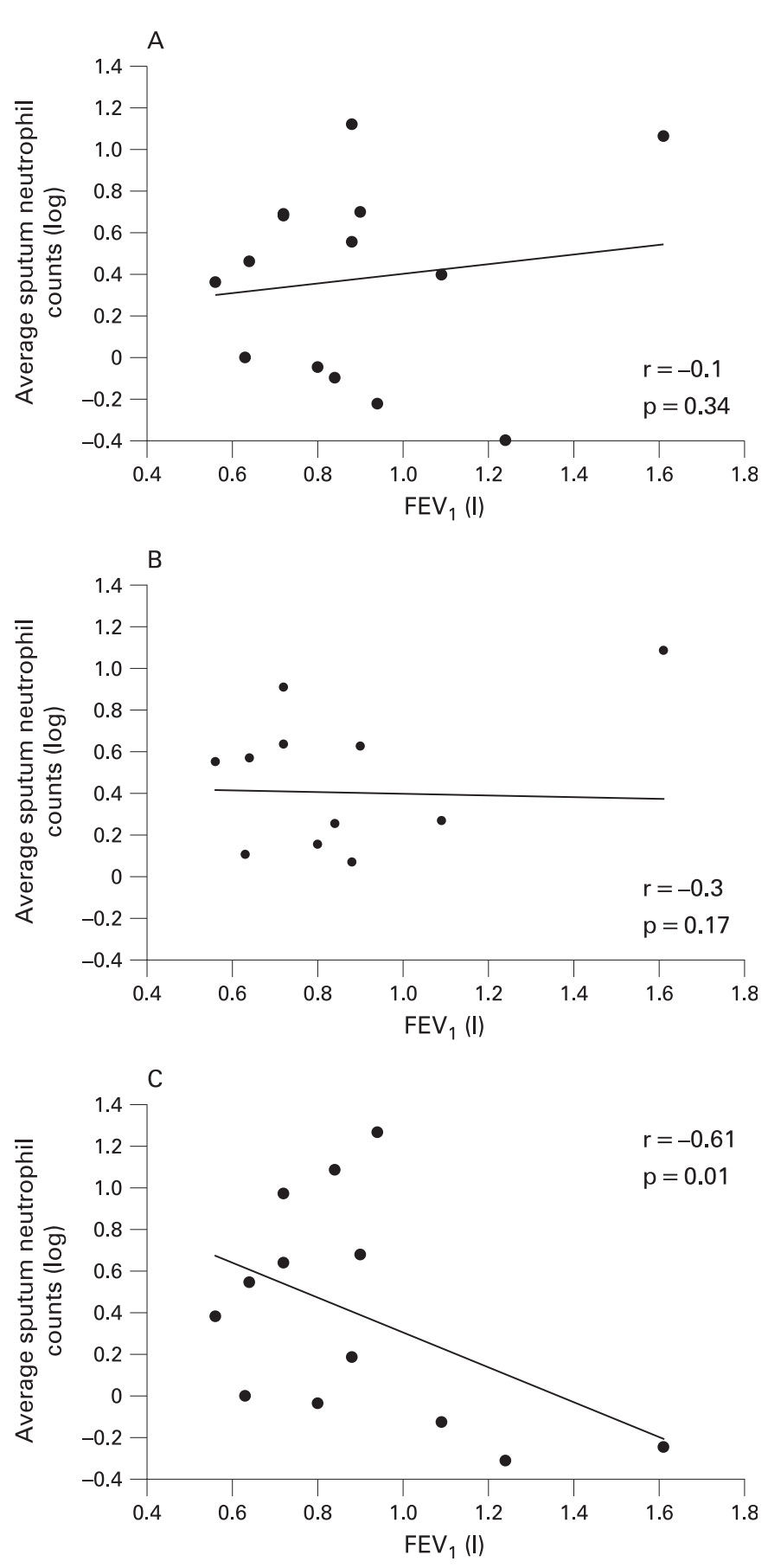

Figure 5 Relationship between forced expiratory volume in $1 \mathrm{~s}\left(\mathrm{FEV}_{1}\right)$ and $(A)$ absolute sputum neutrophil counts using the first day's data for each patient, $(B)$ the mean of the first 3 days' data or $(C)$ the mean of 11 sequential days. In all graphs the sputum neutrophil counts have been log-transformed and the correlation is described using Pearson's correlation coefficient $(r)$ together with the significance of the relationships (p). (A) Data points represent the $\mathrm{FEV}_{1}$ and sputum neutrophil count for each patient on the first visit. (B) Data are shown for individuals using the mean of the first three samples. (C) Data are shown for individuals using the mean of all 11 samples.

for studying inflammatory change in COPD and can be used to power short-term proof of concept studies.

The study demonstrates the positive correlations that exist between sputum inflammatory mediators, neutrophil and macrophage counts, and these biomarkers and other markers of disease severity. By the use of sequential measurements, we have shown that one measurement alone may be insufficient to identify all relationships between mediators. Further sequential sampling reduces the within-patient variability, and using three samples is both reasonable and dramatically reduces the numbers required for both parallel and crossover interventional studies.

Acknowledgements: The authors thank Diane Griffiths, Queen Elizabeth Hospital and Debbie Parker, Glenfield Hospital.

Funding: AstraZeneca sponsored this work with an unrestricted grant.

Competing interests: None.

Ethics approval: The study was approved by the local research ethics committee and all patients gave informed consent.

\section{REFERENCES}

1. de Boer W. Perspectives for cytokine antagonist therapy in COPD. Drug Discov Today 2005;10:93-106.

2. van der Vaart H, Koëter GH, Postma DS, et al. First study of infliximab treatment in patients with chronic obstructive pulmonary disease. Am J Respir Crit Care Med 2005;172:465-9

3. Mahler DA, Huang S, Tabrizi M, et al. Efficacy and safety of a monoclonal antibody recognizing interleukin-8 in COPD. A pilot study. Chest 2004;126:926-34.

4. Gompertz S, Stockley RA. A randomized, placebo-controlled trial of a leukotriene synthesis inhibitor in patients with COPD. Chest 2002;122:289-94.

5. Pinto-Plata V, Toso J, Lee K, et al. Profiling serum biomarkers in patients with COPD: associations with clinical parameters. Thorax 2006;61:23-8.

6. Franciosi LG, Page CP, Celli BR, et al. Markers of disease severity in chronic obstructive pulmonary disease. Pulm Pharmacol Ther 2006;19:189-99.

7. Gompertz S, Bayley DL, Hill SL, et al. Relationship between airway inflammation and the frequency of exacerbations in patients with smoking related COPD. Thorax 2001:56:36-41.

8. Barnes PJ, Chowdhury B, Kharitonov SA, et al. Pulmonary perspective. Pulmonary biomarkers in COPD. Am J Respir Crit Care Med 2006;174:6-14.

9. Pauwels RA, Buist AS, Calverley PM, et al. GOLD Scientific Committee. Global strategy for the diagnosis, management and prevention of Chronic Obstructive Pulmonary Disease. NHLBI/WHO Global Initiative for Chronic Obstructive Lung Disease (GOLD) Workshop summary. Am J Respir Crit Care Med 2001;163:1256-76.

10. Anon. Definition and classification of chronic bronchitis for clinical and epidemiological purposes. A report to the Medical Research Council by their Committee on the aetiology of chronic bronchitis. Lancet 1965;1:775-9.

11. Woolhouse IS, Hill SL, Stockley RA. Symptom resolution assessed using a patient directed diary card during treatment of acute exacerbations of chronic bronchitis. Thorax 2001;56:947-53.

12. Woolhouse IS, Bayley DL, Stockley RA. Effect of sputum processing with dithiothreitol on the detection of inflammatory mediators in chronic bronchitis and bronchiectasis. Thorax 2002; 57:667-71.

13. Snedecor GW, Cochran WG. Statistical methods. 8th ed. Ames: lowa State Press, 1989.

14. Anthonisen NR, Manfreda J, Warren CP, et al. Antibiotic therapy in exacerbations of chronic obstructive pulmonary disease. Ann Intern Med 1987;106:196-204.

15. Rodriquez-Roisin R. Towards a consenus definition of COPD exacerbation. Chest 2000;117(Suppl 2):398-401s.

16. Bhowmik A, Seemungal TA, Sapsford RJ, et al. Comparison of spontaneous and induced sputum for investigation of airway inflammation in chronic obstructive pulmonary disease. Thorax 1998;53:953-6.

17. Biernacki WA, Kharitonov SA, Barnes PJ. Increased leukotriene B4 and 8isoprotane in exhaled breath condensate of patients with exacerbations of COPD. Thorax 2003;58:294-8.

18. Rutgers SR, Timens W, Kaufman HF, et al. Comparison of induced sputum with bronchial wash, bronchoalveolar lavage and bronchial biopsies in COPD. Eur Respir J 2000;15:109-15.

19. Pizzichini MM, Pizzichini E, Clelland L, et al. Prednisone-dependent asthma: inflammatory indices in induced sputum. Eur Respir J 1999;13:15-21.

20. Gamble E, Qiu Y, Wang D, et al. Variability of bronchial inflammation in chronic obstructive pulmonary disease: implications for study design. Eur Respir $J$ 2006;27:293-9.

21. Beeh KM, Beier J, Kornmann 0, et al. Long term repeatability of induced sputum cells and inflammatory markers in stable, moderately severe COPD. Chest 2003;123:778-83.

22. Effros RM, Su J, Casaburi R, et al. Utility of exhaled breath condensate in chronic obstructive pulmonary disease: a critical review. Curr Opin Pulm Med 2005;11:135-9.

23. Borrill Z, Starkey C, Vestbo J, et al. Reproducibility of exhaled breath condensate pH in chronic obstructive pulmonary disease. Eur Respir J 2005;25:269-74.

24. Effros RM, Peterson B, Casaburi R, et al. Epithelial lining fluid solute concentrations in chronic obstructive lung disease patients and normal subjects. J App/ Physiol 2005;99:1286-92 
25. van Zuijlen DA, van de Graaf EA, van Bolhuis EM, et al. Measuring plasma exudation in nasal lavage fluid and in induced sputum as a tool for studying respiratory tract inflammation. J Intern Med 2001;256:1-10.

26. Persson CGA, Erjefalt JS, Greiff L, et al. Plasma derived proteins in airway defence, disease and repair of epithelial injury. Eur Respir J 1998;11:958-70.

27. Erjefalt JS, Sundler F. Eosinophils, neutrophils and venular gaps in the airway mucosa at epithelial removal-restitution. Am J Respir Crit Care Med 1996:153:1666-74.

28. Traves SL, Culpitt S, Russell REK, et al. Elevated levels of the chemokines GRO $\alpha$ and MCP-1 in sputum samples from COPD patients. Thorax 2002;57:590-5.

29. Sapey E, Bayley DL, Ahmad A, et al. Growth related oncogene alpha does not relate to inflammatory change in COPD. Eur Respir J 2005;26(Suppl 49):482s.

30. O'Shaunessy TC, Ansari TW, Barnes NC, et al. Inflammation in bronchial biopsies of subjects with chronic bronchitis, inverse relationship of CD8+ $T$ lymphocytes with FEV1. Am J Respir Crit Care Med 1997;155:852-7.

31. Gompertz S, Hill AT, Bayley DL, et al. Effect of expectoration on inflammation in induced sputum in alpha-1-antitrypsin deficiency. Respir Med 2006;100:1094-9.

32. Vestbo J, Prescott E, Lange P. Association of chronic mucus hypersecretion with FEV1 decline and chronic obstructive pulmonary disease morbidity. Copenhagen City Heart Study Group. Am J Respir Crit Care Med 1996;153:1530-5.

33. Prescott $\mathbf{E}$, Lange P, Vestbo J. Chronic mucus hypersecretion in COPD and death from pulmonary infection. Eur Respir J 1995;8:1333-8.

34. Saetta M, Turato G, Maestrelli $P$, et al. Cellular and structural basis of chronic obstructive pulmonary disease. Am J Respir Crit Care Med 2001;163:1304-9.
35. Hill A, Campbell EJ, Hill SL, et al. Association between airway bacterial load and markers of airway inflammation in patients with stable chronic bronchitis. Am J Med 2000; 109:288-95.

36. Wise RA. The value of forced expiratory volume in one second decline in the assessment of chronic obstructive pulmonary disease progression. Am J Med 2006;119(10 Suppl):4-11.

37. Wright JL, Tai $\mathrm{H}$, Wang $\mathrm{R}$, et al. Cigarette smoke upregulates pulmonary vascular matrix metalloproteinases via TNF-alpha signaling. Am J Physiol Cell Biol Mol Physiol 2007;292:L125-33.

38. Sullivan AL, Stockley RA. Proteinases in COPD. In: Stockley RA, Rennard S, eds Chronic obstructive pulmonary disease. Oxford: Blackwells, 2006:349-66.

39. Wilson D0, Rogers RM, Wright EC, et al. Body weight in chronic obstructive pulmonary disease: the National Institutes of Health intermittent positive pressure breathing trial. Am Rev Respir Dis 1989;139:1435-8.

40. Gray-Donaldson K, Gibbons L, Shappiro SH, et al. Nutritional status and mortality in chronic obstructive pulmonary disease. Am J Respir Crit Care Med 1996;153: 961-6.

41. Mador MJ. Muscle mass and not body weight predicts outcome in patients with chronic obstructive pulmonary disease. Am J Respir Crit Care Med 2002;166:787-9

42. Eid AA, lonescu AA, Nixon LS, et al. Inflammatory response and body composition in chronic obstructive pulmonary disease. Am J Respir Crit Care Med 2001:164:1414-8. 